\title{
Paul Ariste ürgvadjaluse kontseptsioon ja Oudekki Figurova
}

\author{
Madis Arukask
}

Kui Paul Ariste 1942. aasta sõjasuvel esimest korda vadjalaste asuala külastas, leidis ta eest veel jõulise põlvkonna, kes vaatamata sotsialistlikule sundkollektiviseerimisele, ateismipropagandale, vahepealsetele repressioonidele ja alanud sõjavintsutustele mäletas ja tundis hästi seda talupojakeskset maailma, milles olid elanud nende esivanemad pikki aegu. Sellel külaõigeusklikul ühiskonnal oli silmanähtavalt loodust hingestav ja lahkunud esivanematega suhtlev maailmavaade, mida ta jagas samaaegselt muude etniliste rühmadega multinatsionaalsel Ingerimaal. Toona lahkus Paul Ariste rinde tagalast sooviga pöörduda Vadjamaale veel tagasi. Tema ekspeditsioonipäevikus on kirjas:

Vadja innustab. Ja peaasi on, et peab kiirustama. Järgmised uurijad võivad siit leida küll vadja keele kõnelejaid, kuid kiiresti kaovad need, kes tunnevad vana maailma (VE I: 290).

Keeleteadusliku ja folkloristliku ettevalmistuse tõttu jagus Paul Aristel alati huvi ja tähelepanu rahva vaimse pärandi vastu laiemalt. Tänu sellele huvile on säilinud rikkalik etnoloogiline materjal, ilma milleta meie teadmised sellest kaduvast rahvast oleksid määratult õhemad. Käesoleva lühiartikli põhiallikateks ongi Paul Ariste vastavad käsikirjalised talletused (VE).

Paul Ariste tundeline suhe vadjalastega sai alguse juba gümnaasiumipõlves 1920. aastail, mil ta Estonia kontserdisaalis Eesti Ingerist esinema tulnud Daarja Lehtile esitatud küsimusele Oletteko inkeriläinen? sai vastuseks En õlõ. Miä õlõn vana vad'jalain! (Ariste 1970: 89). Just Eesti Ingerisse elama sattunud keelejuhid (Daarja Lehti ja Kigoria Kuzmin) olid Paul Ariste peamised informandid 1942. aastani.

Pärast Teise maailmasõja lõppu muutus Eestiga samass hiidriiki inkorporeeritud Vadjamaa külastamine mõneti lihtsamaks, mistõttu Paul Ariste viibis seal üliõpilastega paljudel suvedel 1947. aastast 1970. aastate lõpuni. Kaheldamatult polnud see enam see Vadja- 


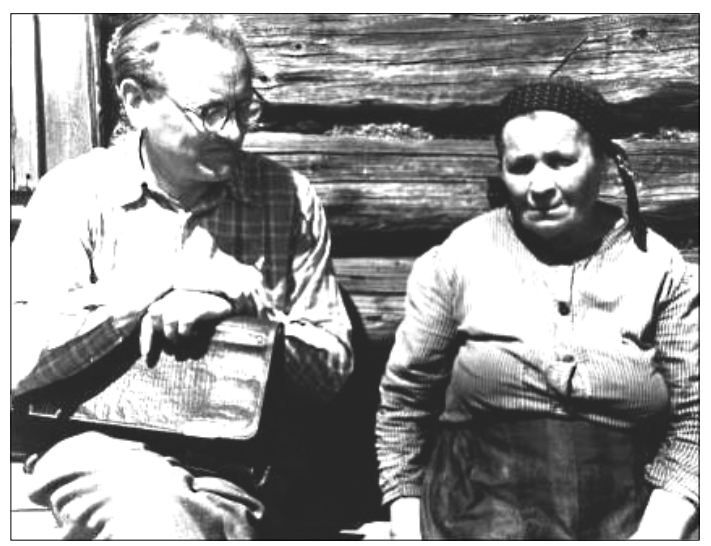

Paul Ariste Vadjamaal 1959. aastal (http://www.ut.ee/Ural/hist.html).

maa, mida Paul Ariste oli saanud näha veel sõja ajal. Kogukondlik süsteem, mida nõukogude kord oli asunud lammutama juba sõja eel, ei taastunud pärast Ingerimaale sõjas osaks saanud katsumusi enam kunagi. Need põlisasukad, kes pärast Eestis, Soomes ja Venemaal oldud sundasumist said kodukohta tagasi pöörduda, leidsid eest mujalt sisserännanud venekeelse elanikkonna ja vaenuliku suhtumise, mis nägi neis ennekõike Nõukogude Liidule ebalojaalset kihti (vt näit vadjalasi, isureid ja ingerisoomlasi käsitlevaid artikleid Vene impeeriumi rahvaste punases raamatus - Kolga jt 1993). Sellises psühholoogilises pressingus nõukogulike loosungite all jõudis lõpule juba enne sõda alanud põliselanikkonna noorema põlvkonna venestumine ja eemaldumine. Mõnevõrra hiljem algas kohtade müümine Peterburi suvitajatele, mistõttu nüüdseks on omaelanikkond vadja külades juba tuntavas vähemuses.

Niisiis oli Paul Ariste pärastsõjaaegne vadja keele ja rahvaluule uurimine samaaegselt ka pidev ühe rahvuse hääbumise tunnistamine. On ootuspärane, et uurija niigi empaatilise lähenemise peatooniks kogumispäevikutes saab nostalgia. Loomulikult oli Paul Ariste ennekõike talletaja, päästja. Tal kujunes välja oma meeliskeelejuhtide võrk, kellele keskendusid ka uurimiskäigud. See kahanes koos rahvuse hääbumisega. Olen arvamusel, et nii jäi kõrvale nii mõnigi teine potentsiaalne informant. Lisaks heale keeleoskusele mängis P. Ariste silmis keelejuhtide puhul olulist rolli ka endise olustiku ja kommete tundmine. Ta oli usuküsimustes 


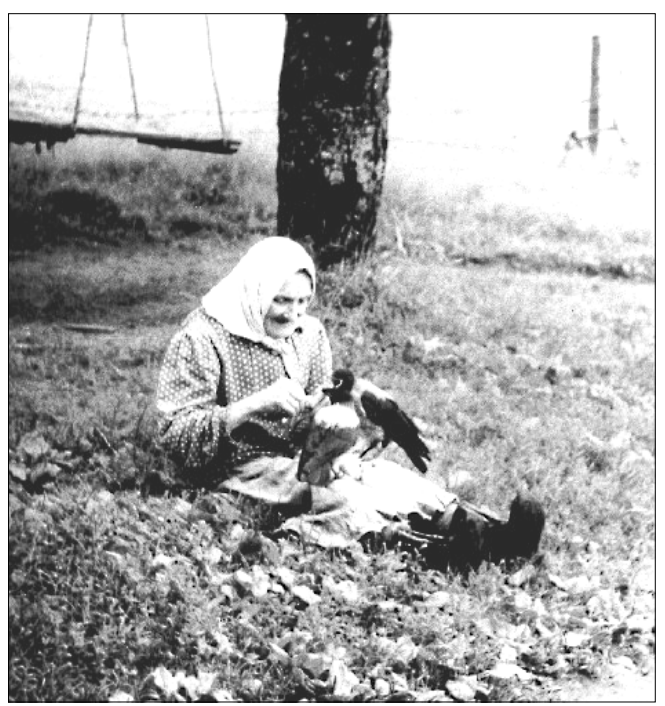

Paul Ariste üks hinnatumaid vadja keelejuhte Rajo külast pärit Oudekki Figorova 1966. aastal. Tõnu Seilenthali foto.

tolerantne. Päevikutes on ta pigem pooldav, trükisõnas ilmunud artiklites neutraalne - asjaolu, mis nõukogude perioodil ei olnud sugugi iseenesestmõistetav või vabaltvõetav. Pole võimatu, et siin (ja kogu suhtumises vadjalastesse) on oma osa võinud olla ka asjaolul, et Paul Ariste oli õigeusklik, ehkki see toona kirjutatud sõnas kusagil esile tulla ei saa.

$P$. Ariste tung kaduva päästmisele ühelt ning ta sisemine nostalgia ja resistants nõukoguliku resp. veneliku vastu, teiselt poolt on olnud aluseks tema ürgvadja kontseptsiooni konstrueerimisel. Sellist epiteeti kasutab ta viimastel aastakümnetel eriti kolme vanema naisinformandi - Marja Boranova, Olga Ivanova (Mati küla) ja Oudekki Figurova (Rajo küla) - maailmapildi ja pärimuse iseloomustamisel. 1966. aasta ekspeditsiooni kommentaarides märgib ta:

On lausa ime, kuipalju Ol'gal ja Marjal on säilinud ürgvadja uskumusi. Nad usuvad kõike seda, mida teavad jutustada. Mõlemad teevad ilmselt vahet kristliku usundi ja vanavadja usundi vahel. Ol'gal on vanavadja usund esikohal (VE X: 13). 
Paul Ariste rõhutas tihti oma eelistust koguda neilt, kes kõnelevad vaid seda, mida ise usuvad, mitte ei räägi mujalt kuuldut ümber. Selliste kõnelejate hulka kuulusid ka eelnimetatud informandid. Kahtlemata hindas aga Ariste üle nende võimet eristada kristlikku algupära ainest muust rahvausundilisest pärimusest, milleks elavas rahvausus õieti vajadust pole. Ta püüdis selekteerida välja vadja usundi, mis vadjalaste pikka aega kestnud hääbumisprotsessi arvestades ei saanud olla kuigi realistlik. Pole kahtlust, et kõnealustel informantidel oli tõepoolest kii-

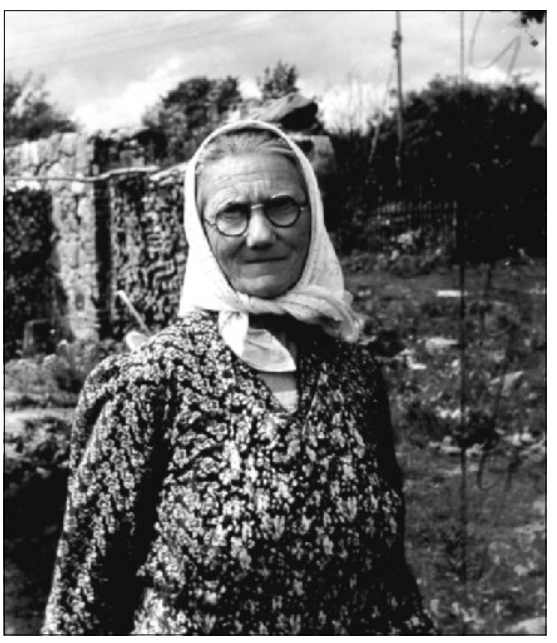

Vadja keelejuht, Mati külast pärit Olga Ivanova 1942. aastal. Foto Paul Ariste kollektsioonist. resti uuenevast ümbrusest oluliselt erinev usundiline maailmavaade. Silmatorkav on Olga Ivanova veendumus kuradist kui metsaasukast. Paul Ariste on seda kommenteerinud järgmiselt:

O. Ivanoval pole kurat põrguelanik nagu kristlastel, vaid kurat elab tema arvates üksnes metsas (VE X: 7; vt ka Ariste 1970: 96).

Kui teda kuulata, võib uskuda, et ollakse tagasi mindud sellesse vadjalaste ajastusse, kus Makaari hakkas neid kristlasteks tegema (VE X: 5).

Tajume siin taas P. Ariste ihalust vadjalasi "rehabiliteerida" neile ajaloo "tagasi andmisega" või evolutsionistliku vastandusega kristlik contra ürgvadja. On ilmne, et keeleteaduslikus plaanis oli vadjalik ka 20. sajandil adekvaatselt välja toodav. Rahvausundilises ja üldkultuurilises plaanis olid piirid isurite ja teiste naabruses elavate etniliste rühmadega aga juba pöördumatult ähmastunud. Kuivõrd Paul Ariste keskendus vadja keele kõnelejatele, võis kergelt juhtuda, et ta hakkas ka nendelt talletatud, kuid piirkonnas üldlevinud mis tahes vanemat pärimuskorpust pidama vaid vadjalastele omaseks ehk ürgvadjalikuks. 
UUS TEEMA

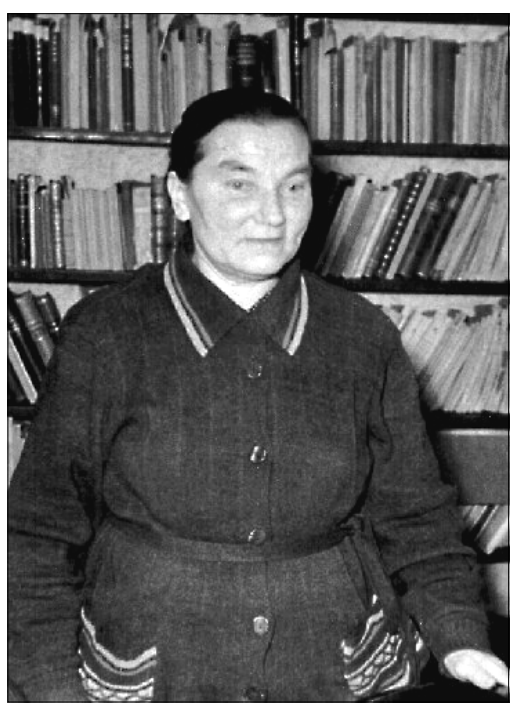

Vadja keelejuht, Mati külast pärit Marja Boranova. Foto Paul Ariste kollektsioonist.
Madis Arukask

Võib öelda, et P. Ariste vajas ürgvadjat samavõrd kui ta arvas seda vajavat oma keelejuhte, kes ilmselt olid reaalse olukorraga juba ammu leppinud. On selge, et mõlemal poolel oli oma nostalgia, kuid see oli välja kasvanud erinevalt pinnalt ja kogemusest. Sellele vaatamata sobitusid uurija ja uuritavate erinevad taustad tavaliselt hästi, teineteist toetades. Kahtlemata ei forsseerinud Paul Ariste oma nägemusi sedavõrd nagu Oskar Loorits omal ajal Liivi rannas, mille tõttu too kuulutati toona Läti Vabariigis persona non grataks. Kuid sellele vaatamata ei saanud keegi keelata P. Aristel uskuda ja näha seda, mida ta uskuda ja näha ihales.

Ürgvadjalik ei eksisteerinud P. Aristele mitte ainult ideena, vaid kehastus ka teatavas ühiskondlikus inimtüübis või rollis. Ennekõike oli see eelkirjeldatud vanu uskumusi tundev ja praktiseeriv vanem vadja keelt valdav suhtlemisaldis naisinformant. Paul Aristel oli ka vähemjutukaid naisinformante, samuti meesinformante, kelle suhtumine varasemasse uskumusmaailma oli aga pigem humoorikas. Tema lemmikuteks olid ja jäid siiski ennekõike Maria Boranova ja Oudekki Figurova, iseäranis viimane tänu oma erilisele habitusele, ravitseja ja lauliku staatusele ning teataval määral traagilisele vastandumisele uuenenud maailmavaatele.

Paul Ariste on tihti kirjeldanud Oudekki Figurovat hea informandina. 1968. aasta päevikus mainib ta näiteks:

Oudekki on küllusesarv. [---] Teda pole vaja kuigi palju küsitleda. Ta teab, mis mind huvitab, ja jutustab ise peaaegu pidevalt. Lahkusin tema juurest tahtmata (VE XII: 102).

Ilmne on, et tegelikult polnud Oudekki Figurova lauliku ega ravitsejana mingi absoluutne lagi. Veel 1947. aastal kohtas ja talletas 
Paul Ariste unikaalset laulurepertuaari tema tädilt, tõeliselt suurlaulikult Matjo Gerassimovalt. Oma ravitsejateadmiste lünklikkust kahetses Oudekki Figurova aga isegi, sest ta täätäjast ema oli keeldunud talle kunagise kohatu pärimise tõttu oma teadmisi edasi andmast (vrd VE XII: 121; XVI: 407). Sellele vaatamata oli Oudekki Figurova ravitsejana tuntud ning hinnatud ka ämmaemanda ja surnupesijana. Paul Ariste ei kõhelnud nimetada teda viimaseks vadja täätäjäks (Ariste 1978: 349).

Oudekki Figurova oli sündinud 14. märtsil 1891 Jõgõperä külas Kunikvallas. Paul Ariste tutvus temaga alles 1964. aastal ja külas-

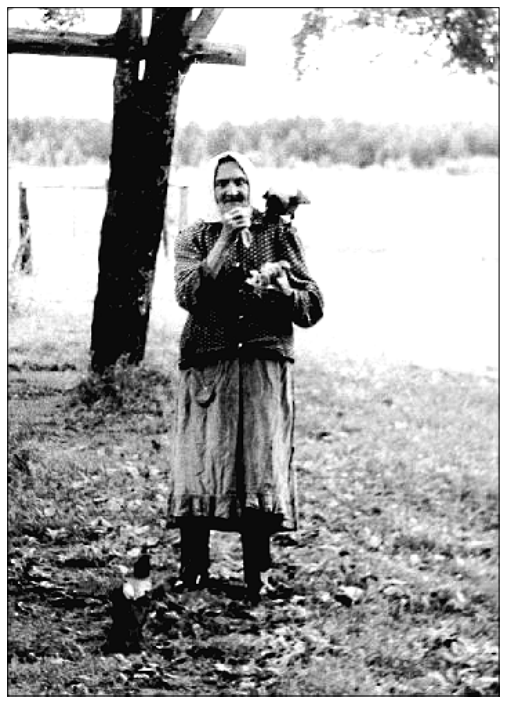

Oudekki Figurova, ôlal kodustatud vares. Tõnu Selilenthali foto 1966. tas teda sellest ajast peale igal oma uurimisretkel. Kokku talletas ta selle aja jooksul 667 (720?) rahvaluulelist teadet.

Oudekki Figurova sündis vadja suurperes, kus ainult üks vanaema oli olnud muulane - Narvusi isur. Peres oli kolm tütart ja poeg, kellest kõik surid enne Oudekkit. Kui Oudekki oli 12-aastane, suri ta isa. Ootuspäraselt pidi Oudekki juba lapsena hakkama tegema mitmesuguseid töid lapsehoidmisest noodapüügini. Koolis oli ta käinud vaid poolteist aastat, kuid oskas sellele vaatamata kirjutada. Nooruses oli ta mõne aasta töötanud ka Narvas tekstiilivabrikus ja teenijana. 20-aastaselt naasis ta kodukülla ja abiellus kohaliku isuriga. Oudekkil oli üheksa last, kellest vaid kaks tütart kasvasid täisealiseks. Kõrge vanuseni säilitas ta hea füüsilise vormi. Veel 80-aastaselt käis ta Lauga jõel õngitsemas.

Seltskondliku inimesena oli ta abielunaise staatusele vaatamata osaline talvisel sanditamisel, kõnelemata pulmadest ja matustest. Ta tundis maarohtusid ning mõistis valmistada salve ja dekokte. Ta oli "mõõtnud" mehe tapetud karu käppi, mis vastavalt rahvapärasele veendumusele andvat ravijavõimed. Ta oskas ravida kätega ja loitsides. 
UUS TEEMA

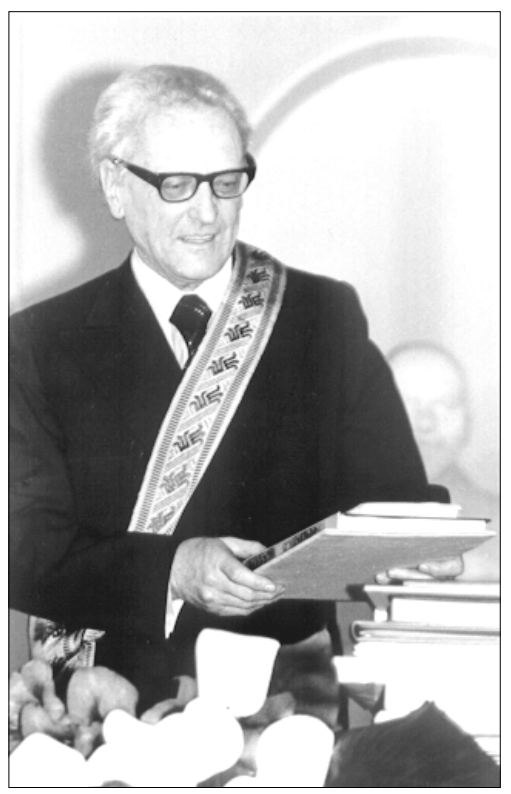

Akadeemik Paul Ariste oma 70. sünnipäeval 1975. aastal Tartus..
Madis Arukask

Võib öelda, et Oudekki Figuroval oli personaalne suhe elava loodusega. Ta on Paul Aristele kirjeldanud oma rituaale metsas marjul käies - "kuldset kuuske", mille alla ta alati toiduohvri viis ning siis teadmata kadunuid mälestas. P. Ariste mainib ka juhtumit, mil Oudekki Figurova oli metsasihil põdraga kokku sattudes jutustanud sellele pika loo oma elust, mida loom oli ka kuulama jäänud ja siis aeglaselt metsa tagasi läinud (vt Ariste 1972: 101). Oudekki Figurova üks ekstravagantsusi oli harakate ja vareste kodustamine, kes teda omaks pidasid. Ootuspäraselt oli see kõik väga muljetavaldav ja kehastas sellisena P. Aristele tema kujutluste Vana-Vadjat.

Muutunud ühiskonnaga läks Oudekki Figurova selline habitus aga ta elu lõpul üha enam konflikti. Ta ei saanud pensioni (see polnud Nõukogude kolhoosnike puhul erandlik), mistõttu ta suhe ametvõimudega oli seda olematum. Tütred ja väimehed ei sallinud tema vadja keeles kõnelemist, vanu pruuke, nendesse uskumist, laulmist ja naermist. Või nagu P. Ariste on kommenteerinud: Tütred tahtsid olla hästi peened (VE XXI: 110).

Ka folkloristidega sai Oudekki Figurova lõpuks suhelda vaid omaste halvakspanuga riskides. Oma viimased laulud laulis ta magnetofonile sisuliselt salaja.

Jõudsime Rajole, kus Oudekki Figurova meid ootas. Olin talle kirjutanud, et tuleme. Oudekki ei kutsunud meid tuppa, vaid palus rõdule. Ta oli kuidagi rõhutud tujus. Ääri-veeri mööda vesteldes ilmnes, et ta peened tütred ei taha, et ema räägib vanadest kommetest, posimisest, laulab vanu laule ja räägib vanu jutte (VE XII: 102, 1968).

Selle pikalt väldanud konflikti traagiliseks lõpuks sai tõsiasi, et Oudekkit ei maetud tema vanades Jõgõperä rahvariietes, nagu ta 
oli soovinud, sest üks tema tütardest müüs need Kingisepa koduloomuuseumile.

Võiksime kokkuvõttes kujutada Ariste ürgvadja kontseptsiooni moodustajaid järgmiselt:

\begin{tabular}{l|ll}
$\begin{array}{l}\text { religioosses } \\
\text { plaanis: }\end{array}$ & $\begin{array}{l}\text { rahvausu eel- } \\
\text { kristlikud } \\
\text { elemendid }\end{array}$ \\
$\begin{array}{l}\text { lingvistilises } \\
\text { plaanis: } \\
\text { ajaloolises } \\
\text { plaanis: }\end{array}$
\end{tabular}

Või graafilisemalt:

religioosne plaan

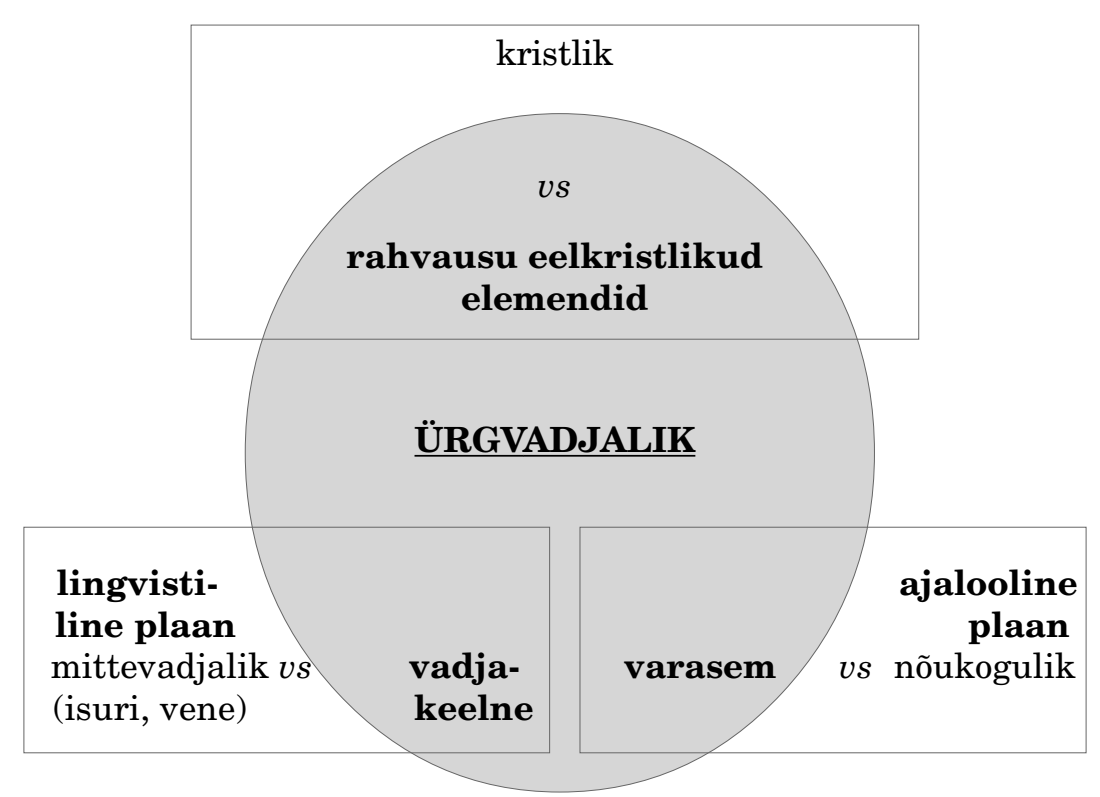


Üksikisiku lõikes joonistub P. Ariste märkmetest sümboolne ürgvadjaluse kandja kui naissooline täätäjä, marginaal,

- kes valdas vabalt vadja keelt;

- kelle mälu ulatus ettepoole nõukogudeaegsest

lauskollektiviseerimisest ja ajupesust;

- kes valdas hea informandina erinevaid folkloorižanre;

- kelle maailmavaates mängis olulist rolli rahvausk (mis

tegelikkuses kristlikku ja mittekristlikku mõistagi ei lahterdanud);

- kes oli mingil moel resistentne uue maailmavaate suhtes;

- kellel oli silmatorkav habitus.

Vaieldamatult vastas just Oudekki Figurova kõige paremini ülalkirjeldatule (eriti kahe viimase punkti osas), täites ja toites nii Paul Ariste nostalgilist uurijaihalust selles kaduvas maailmas. Ehkki P. Aristel oli vadjalaste uurimisel teisigi häid ja veelgi "ürgsemaid" informante, realiseerus ta teadlaseküpsus paljuski just kootöös Oudekki Figurovaga. See on ühtlasi hea näide kahe erineva kogukonna liikme (uurija ja uuritava oma) teineteist toetavast koostööst. Õigupoolest lõppesid Oudekki Figurova surmaga 9. veebruaril 1978 peagi ka juba üsna eaka Paul Ariste suvised Vadja-külastused.

\section{Käsikirjad}

VE - Paul Ariste vadja etnoloogia kogu Eesti Rahvaluule Arhiivis.

\section{Kirjandus}

Ariste, Paul 1970. Vadja rahvaluule võlus. Saaremaast Sajaanideni. Tallinn: Valgus, lk 89-99.

Ariste, Paul 1978. Oudekki Figurova. Keel ja Kirjandus 6, lk 348-350.

Ariste, Paul 1972. Ühest viimasest. Kodumurre 10/11, lk 97-101.

Kolga, Margus \& Tõnurist, Igor \& Vaba, Lembit \& Viikberg, Jüri 1993. Vene impeeriumi rahvaste punane raamat. Tallinn: Vagabund (inglisekeelsena http://www.eki.ee/books/redbook). 